\title{
Hazardous Content Removal and Silver Nanoparticle Recovery from Liquid Radiography Waste Using Microwave Plasma
}

\author{
Andi Erwin Eka Putra*, Enni Sulfiana, Novriany Amaliyah, Azwar Hayat, Hairul Arsyad \\ Mechanical Engineering Department, Faculty of Engineering, Hasanuddin University, Jl. Malino, Borongloe, Bontomarannu, \\ Kabupaten Gowa, Sulawesi Selatan 92119, Indonesia
}

Corresponding Author Email: erwinep@eng.unhas.ac.id

https://doi.org/10.18280/rcma.290605

Received: 9 September 2019

Accepted: 13 November 2019

\section{Keywords:}

hazardous content, silver nanoparticles, the in-liquid plasma, microwave oven, the Debye-Scherrer's formula

\begin{abstract}
The components of liquid radiography waste may be harmful or useful, depending on the composition of the raw material. This paper aims to remove the hazardous content from liquid radiography waste, while recoving the silver nanoparticles. The microwave plasma method was adopted to achieve this purpose. First, the conventional microwave oven was modified to generate the plasma in $100 \mathrm{~mL}$ liquid radiogrpahy waste at $500 \mathrm{~W}$. The plasma generation time was varied for 1, 3, 4, 7, and 10min. In the treated liquid, the total suspended solid (TSS) was analyzed through vultraviolet spectrophotmetry, the silver $(\mathrm{Ag})$ was examined through atomic absorption spectrophometory, and the biological oxygen demand (BOD) and chemical oxygen demand (COD) were discussed by titration method. In addition, the recovered silver was identified by X-ray diffraction (XRD) and scanning electron microscopy (SEM). The results show that the microwave plasma method reduced the TSS by $99.36 \%$, the Ag by $92.73 \%$, the $\mathrm{pH}$ by $3.42 \%$, the BOD by $57.13 \%$, and the COD by $57.14 \%$; In addition, spherical shaped silver nanoparticles were indentified at some peaks with average crystallite size ranging from $2.64 \mathrm{~nm}$ to $65.64 \mathrm{~nm}$. The research findings shed important new light on the recycling of liquid radiography waste.
\end{abstract}

\section{INTRODUCTION}

Medical waste management is one of the numerous complexes and demanding challenges faced by humankind as the worldwide population develop and the demand for medical services increase. Due to improved access to medical services, which permit ever greater numbers of people to gain modern medical care, medical waste production in the developing world is growing rapidly [1].

One of the medical wastes is produced from a radiographic film waste generated in hospital radiology departments for some investigation of medical and dental services. Approximately 2 billion radiographs are taken around the world each year, including chest X-rays, mammograms, CT scans, etc. Several wastes are produced from this medical service such as wastewater containing a photographic chemical, chemicals, and silver removed from the film generated, scrap films, fixer solutions, and spoiled chemicals. Radiography solution waste contains substantial quantities of components that can be both harmful and useful depending on the composition of the raw materials. Thus, for the environmental reasons, it is important to eliminate the high concentration of Silver (Ag), Biochemical Oxygen Demand (BOD), Chemical Oxygen Demand (COD) and Total Suspended Solids (TSS) [2]. Forward osmosis (FO) method was applied to concentrating radioactive liquid waste produced from a radiation therapy room in the hospital. In order to achieve an optimal condition, the $\mathrm{pH}$ and draw solution (DSs) were varied for FO concentration. As a result, this method had a rejection rate of removing natural and radioactive iodine up to $99.3 \%$ [3].
In a previous study, silver recovery from the waste fixer solution examined using the electrolysis method. The highest silver recovery efficiency was $83.88 \%$ which obtained by electric currents of 0.9 A during $8 \mathrm{~h}$ electrolysis procedure. However, COD still had high concentration after electrolysis process so that the distillation process still needed to remove it [2]. Various plasma method has been reviewed for metal recovery from metal-containing waste. A sophisticated purification effect obtained when using the plasma arc melting method, while high energy achieved using plasma arc generated by gas ionization [4].

Several studies investigating the synthesis of particulate matter were done by microwave plasma processes [5-9]. Microwave plasma was generated by modification of microwave oven $[10,11]$. Consider other types of electrical excitation, microwave energy has a higher degree ionization and dissociation thus can enhance the kinetics to initiate a chemical reaction and reduce the activation energy. Moreover, in comparison to standard thermal reaction or thermal plasma, microwave plasma has a lower temperature that was favourable for synthesizing smaller particles [6]. In the solution plasma method for producing nanoparticles mostly requires a simple experimental setup without gas supply and can be utilized to any conductive metal or alloy [12].

Microwave plasma method has been successfully used as a method to synthesized nanoparticles. Most nanoparticles are synthesized at high temperature activated by plasma to enhance chemical reactivity and rapidly contact the liquid for the cooling process. Using a $2.45 \mathrm{GHz}$ microwave with $250 \mathrm{~W}$ of input power, a zinc, and zinc oxide nanoparticles were produced with $3.3 \mathrm{~g} / \mathrm{h}$ of production rate [13]. Compare to 
pulse laser ablation in liquid method, higher productivity (production rate) and efficiency (production amount per energy) can be achieved in synthesis of zinc oxide, silver and magnesium-hydroxide nanoparticles [14]. Zinc nanoparticles was also successfully produced from the reduction of zinc oxide powder using ethanol as a reducing agent using a microwave plasma generator [15]

The objective of this study is to remove hazardous content as well as recover silver nanoparticle from liquid radiography waste using microwave plasma method.

\section{EXPERIMENTAL PROCEDURES}

The experimental apparatus was shown in Figure 1. Plasma was generated using a conventional microwave oven with dimension $470 \mathrm{~mm}$ width, $330 \mathrm{~mm}$ depth and $310 \mathrm{~mm}$ height. The microwave was modified by cutting the heat area and replaced with a waveguide. Microwave output was $85 / 500$ Watt at $2450 \mathrm{MHz}$. A reactor and reservoir made from a polycarbonate cylinder and Teflon were used to gather radiography liquid waste.

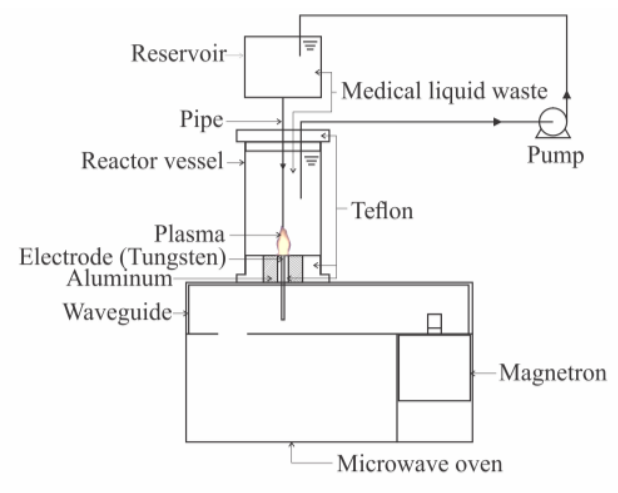

Figure 1. Experimental apparatus
Radiography liquid waste was collected from the radiology department from the hospital. A $100 \mathrm{ml}$ radiography liquid waste was circulated from a reservoir to a reactor which temperature maintained at $93^{\circ}$ to $100^{\circ} \mathrm{C}$. Plasma was generated at $500 \mathrm{~W}$ microwave oven power at atmospheric pressure. Plasma generation time was varied for 1, 3, 4, 7, and 10 minutes. The treated liquid then analysed using UV-2900 PC Spectrophotometer for TSS analysis, AA 700 SHIMADZU for $\mathrm{Ag}$ analysis, and titration method for BOD and COD analysis.

Sample from 10 minutes (sample 1) and 3 minutes (sample 2) of treated radiography liquid waste were dried to get the dry powder. The synthesized materials were identified using XRay Diffraction (XRD) (Shimadzu XRF-7000L) and Scanning electron microscopy (SEM, JEOL JSM-6510 LA).

\section{RESULTS AND DISCUSSION}

\subsection{Hazardous content removal}

Table 1 shows the analysis parameter of liquid waste before and after the first plasma treatment. In order to determine the level of contamination, Chemical Oxygen Demand (COD) and Biological Oxygen Demand (BOD) values play a significant role. The amount of organic matter in the water is indicated by COD and the amount of oxygen required for microorganisms to decompose organic matter in the aerobic conditions is identified by BOD. After plasma irradiation COD and BOD were decreased from $33337.0 \mathrm{ppm}$ to $14286.4 \mathrm{ppm}$ (57.13\%) and $13336.0 \mathrm{ppm}$ to $5716.2 \mathrm{ppm}(57.14 \%)$ respectively, however these results still not fulfil the environmental standard [16]. The longer plasma irradiation time was still difficult to obtain due to the limitation of modified microwave plasma oven apparatus. Nonetheless, Silver contents was decreased from $0.2354 \mathrm{ppm}$ to $0.0171 \mathrm{ppm}(92.73 \%)$ and TSS was decreased from $328.0 \mathrm{ppm}$ to $2.09 \mathrm{ppm}(99.36 \%)$. These values were far below the environmental standard regulation [16].

Table 1. Analysis parameters of medical liquid waste

\begin{tabular}{|c|c|c|c|c|c|c|c|}
\hline \multirow{3}{*}{$\begin{array}{c}\text { Analysis } \\
\text { Parameter }\end{array}$} & \multirow{3}{*}{ Unit } & \multirow{3}{*}{$\begin{array}{c}\text { Analysis before plasma } \\
\text { treatment }\end{array}$} & \multicolumn{5}{|c|}{ Analysis after plasma treatment } \\
\hline & & & \multicolumn{5}{|c|}{ Time (minutes) } \\
\hline & & & 1 & 2 & 4 & 7 & 10 \\
\hline \multicolumn{8}{|c|}{ PHYSICS } \\
\hline TSS & ppm & 328.0 & 1.37 & 1.54 & 0.92 & 1,24 & 2,09 \\
\hline \multicolumn{8}{|c|}{ CHEMICAL } \\
\hline $\mathrm{Ph}$ & & 4.67 & 4.86 & 4.86 & 4.85 & 4,86 & 4,83 \\
\hline Silver (Ag) & ppm & 0.2354 & 0.062 & 0.0155 & 0.0064 & 0,0195 & 0,0171 \\
\hline BOD & ppm & 13336 & 11143 & 9287 & 7144 & 6329 & 5716 \\
\hline COD & ppm & 33337 & 28573 & 23215 & 17858 & 15745 & 14286 \\
\hline
\end{tabular}

Plasma irradiation time gave a significant effect on COD, BOD, and Silver content. The longer plasma irradiation time reduced the concentration of BOD, COD, and Silver. Plasma in contact with liquid can drives $\mathrm{OH}$ production and generates a host of reactive species that attack and ultimately mineralize and destruct organic contaminants in the solution [17]. Due to the presence of hydrogen atoms in water molecule, which was essential for the formation of $\mathrm{OH}$ groups, In-liquid plasma system has a higher $\mathrm{OH}$ selectivity. Maximum $\mathrm{OH}$ selectivity at underwater plasma system was obtained at 3 to 5 minutes treatment duration [18]. When using DC arc plasma method, the amount of COD and BOD of olive mill wastewater reported decreased by $94.42 \%$ and $95.37 \%$ as a result of the dissolved oxygen ratio by means of structures such as ion, photons, free radicals and neutrals provided by plasma to the environment [19].

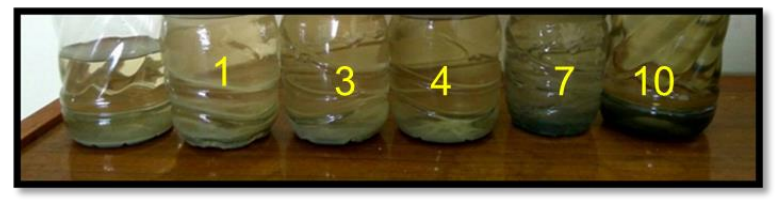

Figure 2. Liquid waste colour change

After plasma treatment, there was some powder dispersed at the bottom of the reactor. There was a color change in that powder at 1-minute plasma irradiation. The powder was 
turning into black at 10 minutes plasma irradiation observed by the naked eye as shown in Figure 2. The black powder dispersed at the bottom was assumed to be silver recovered by the plasma treatment.

\subsection{XRD analysis}

After the second plasma treatment of black powder dispersed obtained using ethanol liquid, the synthesized materials were analyzed using X-Ray Diffraction (XRD) (Shimadzu XRF-7000L). For the preparation of the XRD sample, materials dispersion was filtered using a membrane filter (pore size $=0.5 \mu \mathrm{m}$ ). Figure 3 and 4 show the pattern of Silver (Ag) nanoparticles with a value ranging from 10 to 70 .
Figure 3 shows the XRD pattern of sample 1. There were five diffraction peaks specific for silver nanoparticles at $27.7^{0}$, $29.8^{0}, 33.68^{\circ}, 38.8^{0}$ and $47.86^{\circ}$. The peak at $27.7^{0}$ in accordance with silver nanoparticle peak produced from the biosynthesis of Coleus aromaticus leaf extract and biosynthesis of colloidal silver nanoparticles which could be indexed to the (111) plane of silver [20, 21]. The peaks observed at $29.8^{\circ}$ and $33.68^{\circ}$ correspond to (200) and (220) respectively lattice planes for silver, the same peaks also observed when synthesized silver nanoparticles by treating the supernatant from a culture of Escherichia Coli with silver nitrate [22]. The peak confirmed at $47.86^{\circ}$ match that observed in silver nanoparticle synthesized from Pinus densiflora young cone extract [23].

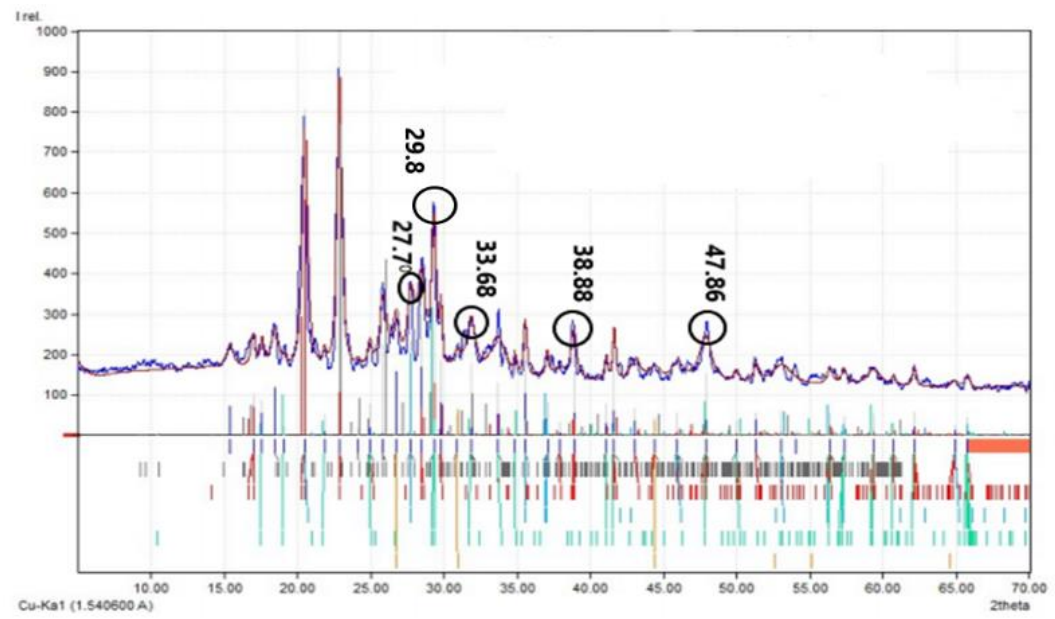

Figure 3. XRD pattern of Silver nanoparticles in sample 1

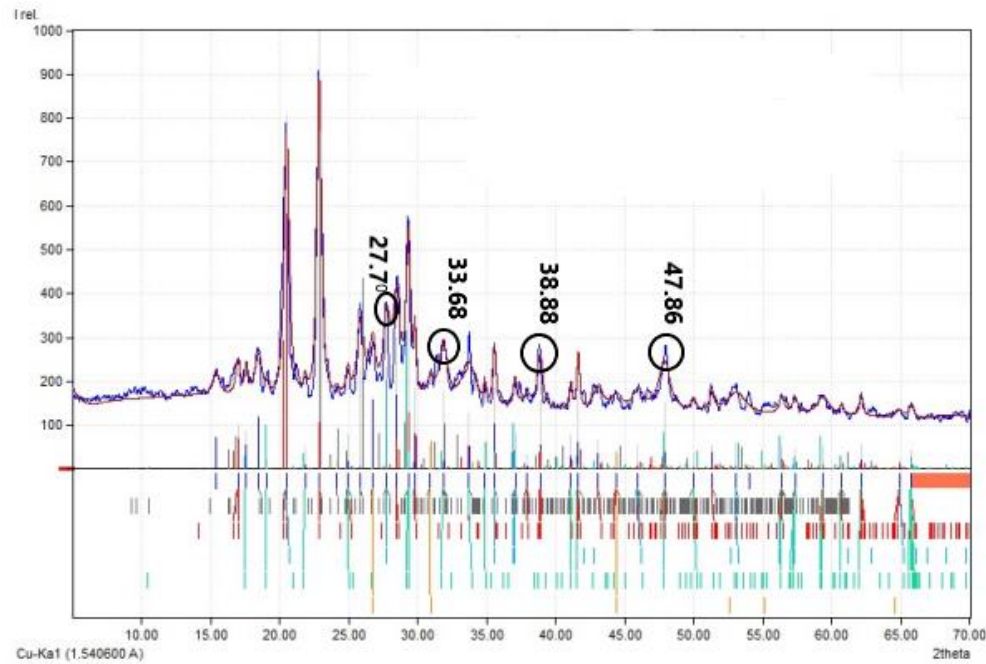

Figure 4. XRD pattern of Silver nanoparticles in sample 2

Figure 4 shows the XRD pattern of sample 2. The same peaks with sample 1 were detected at $27.7^{\circ}, 33.68^{\circ}$, and $38.8^{\circ}$ with higher intensity. The other peak observed at $47.68^{\circ}$ confirmed as silver nanoparticle and can be assigned the plane of $(200)[20,21,24]$. A few unassigned intense peaks were also observed at $20.5^{\circ}$ and $22.8^{\circ}$ in sample 1 and 2 . It is assumed to be carbon peak as EDS result also confirmed the high concentration of carbon was detected at the material synthesized.

The crystallite size of silver nanoparticles (D) was calculated from the Debye-Scherrer's formula [25].

$$
D=\frac{K \cdot \lambda}{\beta \cdot \cos \theta}
$$

where, $\mathrm{K}$ is the Scherrer constant with value from 0.9 to $1, \lambda$ is the wavelength of $\mathrm{x}$-ray source $(0.1541 \mathrm{~nm}), \beta$ is the full width at half maximum (FWHM) of the measured reflection and $\theta$ is the angle of diffraction. The average size of silver nanoparticles as estimated using the above formula was 2.64 to $65.64 \mathrm{~nm}$. 


\subsection{SEM analysis}

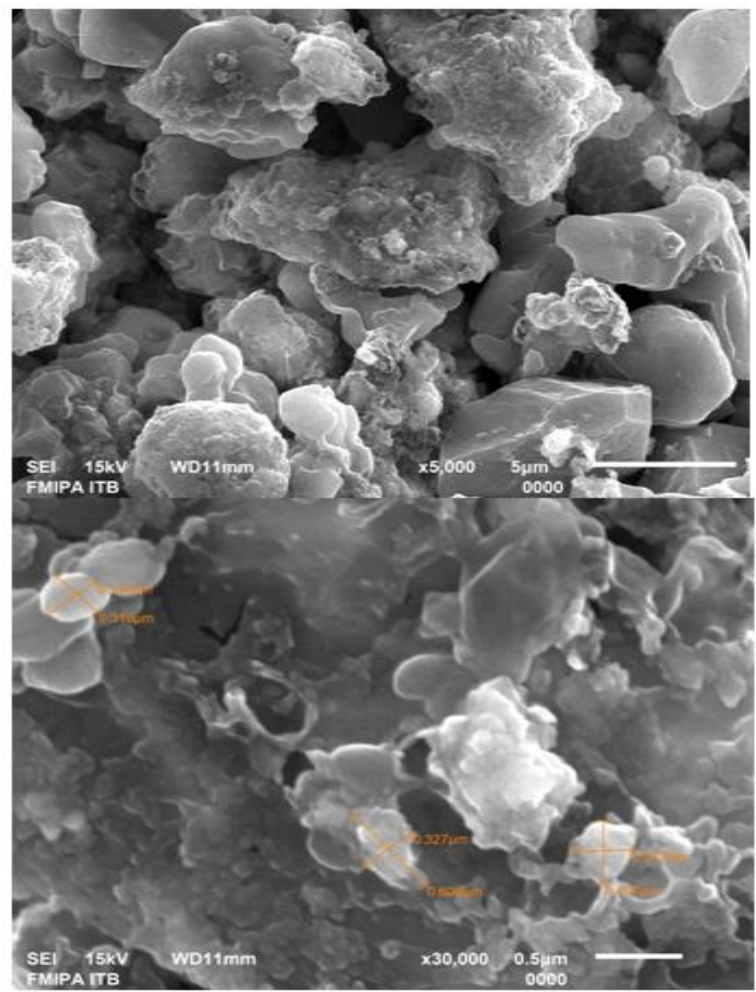

(a)

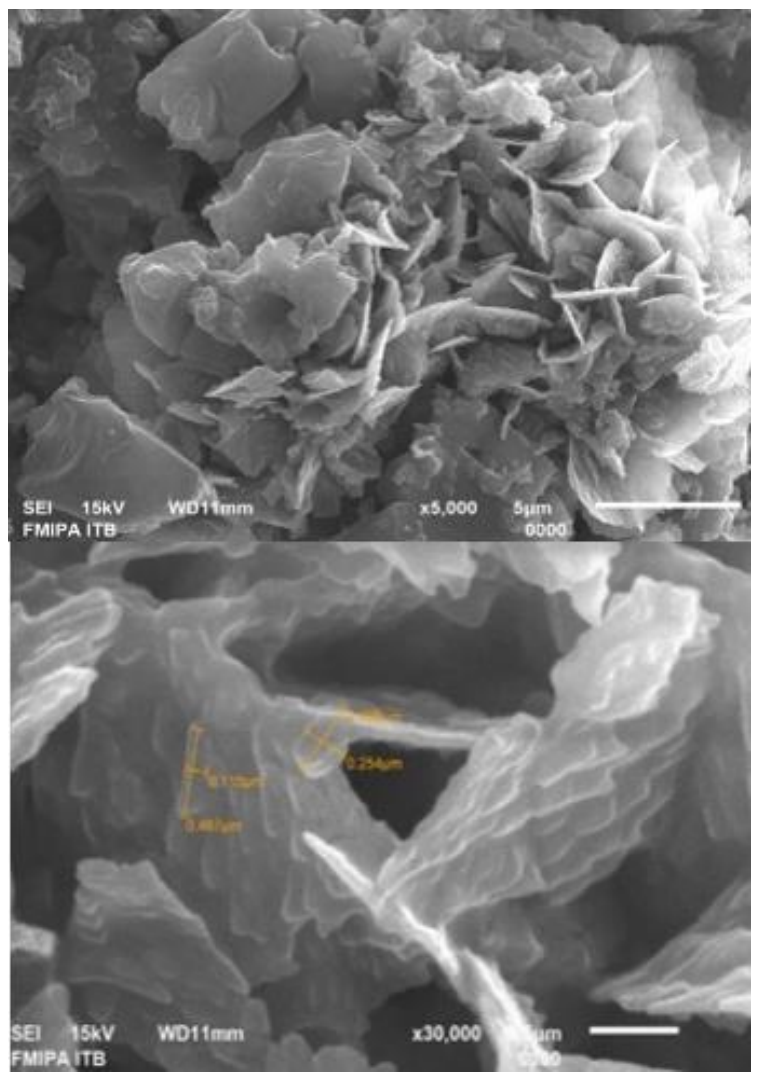

(b)

Figure 5. SEM Image of Silver Nanoparticles, sample 1 (a) and sample 2 (b)

The SEM image in Figure 5 shows the surface morphology of the silver nanoparticles from sample 1 and 2 . The size of spherical shaped silver nanoparticles was ranging from 100$500 \mathrm{~nm}$. Similar shape result of silver nanoparticles was obtained in references [26, 27].

\section{CONCLUSION}

The hazardous content removal and silver nanoparticles recovery from radiography liquid waste were successfully carried out using a modified microwave plasma. Application of plasma technology in radiography liquid waste treatment shows a decrease in TSS levels of $99.36 \%$, Silver $(\mathrm{Ag})$ of $92.73 \%, \mathrm{pH}$ of $3.42 \%$, BOD (Biochemical Oxygen Demand) of $57.13 \%$, and COD (Chemical Oxygen Demand) of $57.14 \%$.

Average crystallite size of XRD results was calculated of 2.64 to $65.64 \mathrm{~nm}$ and SEM results showed spherical shaped nanoparticle.

\section{ACKNOWLEDGMENT}

This work is supported by internal grant of Hasanuddin University, Indonesia (Grant numbers: 5639/UN4.21/PL.00.07/2018) and SEM Laboratory of Faculty of Mathematics and Natural Sciences (FMIPA), Institut Teknologi Bandung (ITB).

\section{REFERENCES}

[1] Windfeld, E.S., Brooks, M.S.L. (2015). Medical waste management - A review. Journal of Environmental Management, 163: 98-108. https://doi.org/10.1016/j.jenvman.2015.08.013

[2] Chen, W.T., Ma, C.C., Lee, M.H., Chu, Y.C., Tsai, L.C., Shu, C.M. (2012). Silver recovery and chemical oxygen demand (COD) removal from waste fixer solutions. Applied 100: 187-192. https://doi.org/10.1016/j.apenergy.2012.06.026

[3] Lee, S., Kim, Y., Park, J., Shon, H.K., Hong, S. (2018). Treatment of medical radioactive liquid waste using Forward Osmosis (FO) membrane process. Journal of Membrane Science, 556: 238-247. https://doi.org/10.1016/j.memsci.2018.04.008

[4] Du, C.M., Chao, S., Gong, X.J., Ting, W., Wei, X.G. (2018). Plasma methods for metals recovery from metal - containing waste. Waste Management, 77: 373-387. https://doi.org/10.1016/j.wasman.2018.04.026

[5] Hattori, Y., Nomura, S., Mukasa, S., Toyota, H., Inoue, T., Kasahara, T. (2013). Synthesis of tungsten trioxide nanoparticles by microwave plasma in liquid and analysis of physical properties. Journal of Alloys and Compounds, 560: 105-110. https://doi.org/10.1016/j.jallcom.2013.01.137

[6] Szabó D.V., Schlabach, S. (2014). Microwave plasma synthesis of materials-from physics and chemistry to nanoparticles: A materials scientist's viewpoint. Inorganics, 2(3): 468-507. https://doi.org/10.3390/inorganics2030468

[7] Nishimoto, M., Yonezawa, T., Čempel, D., Nguyen, M.T., Ishida, Y, Tsukamoto, H. (2017). Effect of $\mathrm{H}_{2} \mathrm{O}_{2}$ on $\mathrm{Au}$ nanoparticle preparation using microwaveinduced plasma in liquid. Materials Chemistry and Physics, 
https://doi.org/10.1016/j.matchemphys.2017.02.009

[8] Koo, J., Lee, J., Kim, J., Jang, B. (2016). Effect of hydrogen on the microstructure and electrochemical properties of Si nanoparticles synthesized by microwave plasma. Materials Chemistry and Physics, 180: 332-340. https://doi.org/10.1016/j.matchemphys.2016.06.015

[9] Kim, J., Sakakita, H., Ohsaki, H., Katsurai, M. (2015). Microwave-excited atmospheric pressure plasma jet with wide aperture for the synthesis of carbon nanomaterials. Japanese Journal of Applied Physics, 54. https://doi.org/10.7567/JJAP.54.01AA02

[10] Putra, A.E.E., Nomura, S., Mukasa, S., Toyota, H. (2014). Hydrogen production by reforming clathrate hydrates using the in-liquid plasma method. In Progress in Sustainable Energy Technologies: Generating Renewable Energy, I. Dincer, A. Midilli, H. Kucuk, ed. (Springer, Cham), pp. 499-507. https://doi.org/10.1007/978-3-319-07896-0_30

[11] Nomura, S., Putra, A.E.E., Toyota H., Mukasa S., Yamashita, H. (2011). Fuel gas production by plasma in a microwave oven at atmospheric pressure. ASME/JSME, 8th Thermal Engineering Joint Conference. T20056-T20056-6. https://doi.org/10.1115/AJTEC2011-44365

[12] Saito, G., Akiyama, T. (2015). Nanomaterial synthesis using plasma generation in liquid. Journal of Nanomaterials, $1-21$. http://dx.doi.org/10.1155/2015/123696

[13] Hattori, Y., Mukasa, S., Toyota, H., Inoue, T., Nomura, S. (2011). Synthesis of zinc and zinc oxide nanoparticles from zinc electrode using plasma in liquid. Materials Letters, 65(2): 188-190. https://doi.org/10.1016/j.matlet.2010.09.068

[14] Hattori, Y., Mukasa, S., Toyota, H., Inoue, T., Nomura, S. (2011). Continuous synthesis of magnesiumhydroxide, zinc-oxide, and silver nanoparticles by microwave plasma in water. Materials Chemistry and Physics, 131(1-2): 425-430. https://doi.org/10.1016/j.matchemphys.2011.09.068

[15] Amaliyah, N., Mukasa, S., Nomura, S., Toyota, H. (2015). Plasma in-liquid method for reduction of zinc Oxide in zinc nanoparticle synthesis. Materials Research Express, 2(2). https://doi.org/10.1088/2053$1591 / 2 / 2 / 025004$

[16] The President of the Republic of Indonesia. (1994). Government regulation No. 19. Regulation regarding hazardous and toxic waste management.

[17] Foster, J.E. (2017). Plasma-based water purification: Challenges and prospects for the future. Physics of Plasmas, 24(055501): 0-16. https://doi.org/10.1063/1.4977921

[18] Joshi, R., Schulze, R.D., Meyer-plath, A., Friedrich, J.F. (2008). Selective surface modification of poly (propylene) with $\mathrm{OH}$ and $\mathrm{COOH}$ groups using liquidplasma systems. Plasma Processes and Polymers, 5(7): 695-707. https://doi.org/10.1002/ppap.200700175

[19] Ibrahimoglu, B, Yilmazoglu, M.Z. (2018). Disposal of olive mill wastewater with DC arc plasma method. Journal of Environmental Management, 217: 727-734. https://doi.org/10.1016/j.jenvman.2018.03.134

[20] Vanaja, M., Annadurai, G. (2013). Coleus aromaticus leaf extract mediated synthesis of silver nanoparticles and its bactericidal activity. Applied Nanoscience, 3(3): 217-223. https://doi.org/10.1007/s13204-012-0121-9

[21] Shivananda, C.S., Asha, S., Madhukumar, R., Satish, S., Narayana, B., Byrappa, K., Wang, Y.J., Sangappa, Y. (2016). Biosynthesis of colloidal silver nanoparticles: Their characterization and antibacterial activity. Biomedical Physics Engineering Express, 2(3): 035004. https://doi.org/10.1088/2057-1976/2/3/035004

[22] Han, J.W., Gurunathan, S., Jeong, J.K., Choi, Y.J., Kwon D.N., Park, J.K., Kim, J.H. (2014). Oxidative stress mediated cytotoxicity of biologically synthesized silver nanoparticles in human lung epithelial adenocarcinoma cell line. Nanoscale Research Letters, 9(1): 459. https://doi.org/10.1186/1556-276X-9-459

[23] Velmurugan, P., Park, J.H., Lee, S.M., Jang, J.S., Lee, K.J., Han, S.S., Lee, S.H., Cho, M., Oh, B.T. (2015). Synthesis and characterization of nanosilver with antibacterial properties using Pinus densiflora young cone extract. Journal of Photochemistry and Photobiology B: Biology, 147: 63-68. https://doi.org/10.1016/j.jphotobiol.2015.03.008

[24] Vanaja, M., Gnanajobitha, G., Paulkumar, K., Rajeshkumar, S. (2013). Phytosynthesis of silver nanoparticles by Cissus quadrangularis: influence of physicochemical factors. Journal of Nanostructure in Chemistry, 3: 17. https://doi.org/10.1186/2193-8865-317

[25] Awwad, A.M., Salem, N.M. (2012). Green synthesis of silver nanoparticles by mulberry leaves extract. Nanoscience and Nanotechnology, 2(4): 125-128. https://doi.org/ 10.5923/j.nn.20120204.06

[26] Ganesan, V., Deepa, B., Nima, P., Astalakshmi, A. (2014). Bio-inspired synthesis of silver nanoparticles using leaves of millingtonia hortensis L. F. International Journal of Advanced Biotechnology and Research, 5(2): 93-100.

[27] Princy, G., Saravanan, P., Gandhi, N.N., Renganathan, S. (2011). A novel approach for studying the combined antimicrobial effects of silver nanoparticles and antibiotics through agar over layer method and disk diffusion method. Digest Journal of Nanomaterials and Biostructures, 6(4): 1557-1565.

\section{NOMENCLATURE}

$\mathrm{D}$

K

the crystallite size of silver nanoparticles, $\mathrm{nm}$ the Scherrer constant

\section{Greek symbols}

$\lambda$ the wavelength of $\mathrm{x}$-ray source, $\mathrm{nm}$

$\beta \quad$ the full width at half maximum (FWHM) of the measured reflection
the angle of diffraction 